\title{
Eribulin Mesylate
}

National Cancer Institute

\section{Source}

National Cancer Institute. Eribulin Mesylate. NCI Thesaurus. Code C26644.

The mesylate salt of a synthetic analogue of halichondrin B, a substance derived from a marine sponge (Lissodendoryx sp.) with antineoplastic activity. Eribulin binds to the vinca domain of tubulin and inhibits the polymerization of tubulin and the assembly of microtubules, resulting in inhibition of mitotic spindle assembly, induction of cell cycle arrest at G2/M phase, and, potentially, tumor regression. 